\title{
Economical Solar Water Heater
}

\author{
S.D. Gangane, S.H. Bhere, L. K. Chinchole, P. A. Dudhalkar, \\ V. D. Nandan, S. S. Sarawade \\ (Department Of Mechanical Engineering, M.E.S. College Of Engineering, S.P.Pune University, India)
}

\begin{abstract}
This paper deals with study, analysis and design of Economical Solar Water Heater. Solar collectors, storage tanks and heat transfer fluids are the three core components in solar water heater applications. Among all flat plate collector type solar water heater is the most efficient. The development of an efficient low cost flat plate collector is an essential first step toward effective utilization of solar energy for water heating. Our aim is to develop solar water heater at the affordable price and test the prototype for efficiency. Replacement of Copper material with Aluminum will make it affordable. The floating assembly helps the system to extract the hot water from supply tank. The objective is to design, fabricate and test prototype of flat plate collector type solar water heater. The maximum temperature attended by the system is $78^{\circ} \mathrm{C}$. The price of economical solar water eater is 11,120/- for 100 LPD.
\end{abstract}

Keywords : Flat plate solar collector, Floating assembly, Thermosyphon Principle.

\section{Introduction}

Fossil fuel resources are primarily used to generate power and heat our homes. It is easy to use coal, oil and natural gas for energy needs of human, but the limited supply of these fuels because of continuous use of these sources cause to diminish it [1].Renewable energy sources are the resources which undergoes faster replacement rate then the rate at which they are used or depleted [2]. There are so many renewable energy sources and solar energy is the one of the type of renewable energy sources. One of the promising options to make more extensive use home of renewable sources of energy derived from the sun [6]. The earth's total power requirement is 15 terawatts. But the solar radiation that riches the earth are 120,000 terawatts, thus the bulk of energy requirement will be covered buy just a fraction of the sun's energy reaching the earth. The major gain of solar energy is that no fuel is necessarily required which directly resist the emission of carbon dioxide which is one of the factor of air pollution [2].Solar energy can be used two ways directly or indirectly. The energy radiation conversion into thermal energy is done with the help of solar collectors [6]. The Solar collector is the initial element of thermal solar installation. The Solar installation are often used in domestic sectors for water heating. Solar collector absorbs the incoming solar radiation converting it into thermal energy had the absorbing surfaces and transferring the energy to the fluid flowing through the collector [3]. Out of the total energy consumption in home almost $20 \%$ of energy it's consumed for water heating. For an average family as it is cost effective where to reduce energy cost from gas, electricity or propane sources and also pollution free which is most beneficial to homeowners as they produce large amount of hot water every day [1].The existing solar water heater consists of cylindrical glass tube that works as the receiver of solar energy and copper coil through which the water flows that is placed inside the glass tube and act as the collector. The technical and environmental performance of solar water heater is examined using the method of life cycle assessment [1].

\section{Objectives}

1. To provide a cost effective solar water heater having aluminum body integrated with natural circulation and hot water storage system.

2. To provide an extraction system having floating ball and flexible pipe in order to get upper layer warm water from the reservoir tank.

3. To provide a solar water heater using aluminum as a primary and the copper as the secondary conducting material.

\section{Working}

Fig.3.1 is the prototype of Economical Solar Water Heater. Prototype gives heat enhancement with minimum losses by small changes in traditional setup.As the name indicates the prototype relates to the solar water heating process. In general, hot water in the tank floats at the top and the cold one at the bottom as shown in Fig. 3.1.This happens due to density difference. At the Bottom there is real water outlet from where the water is 
supplied to tap. In order to get the hot water from the tank it is necessary to extract the upper layer of the water from the tank as the temperature of the water is already high in this layer.

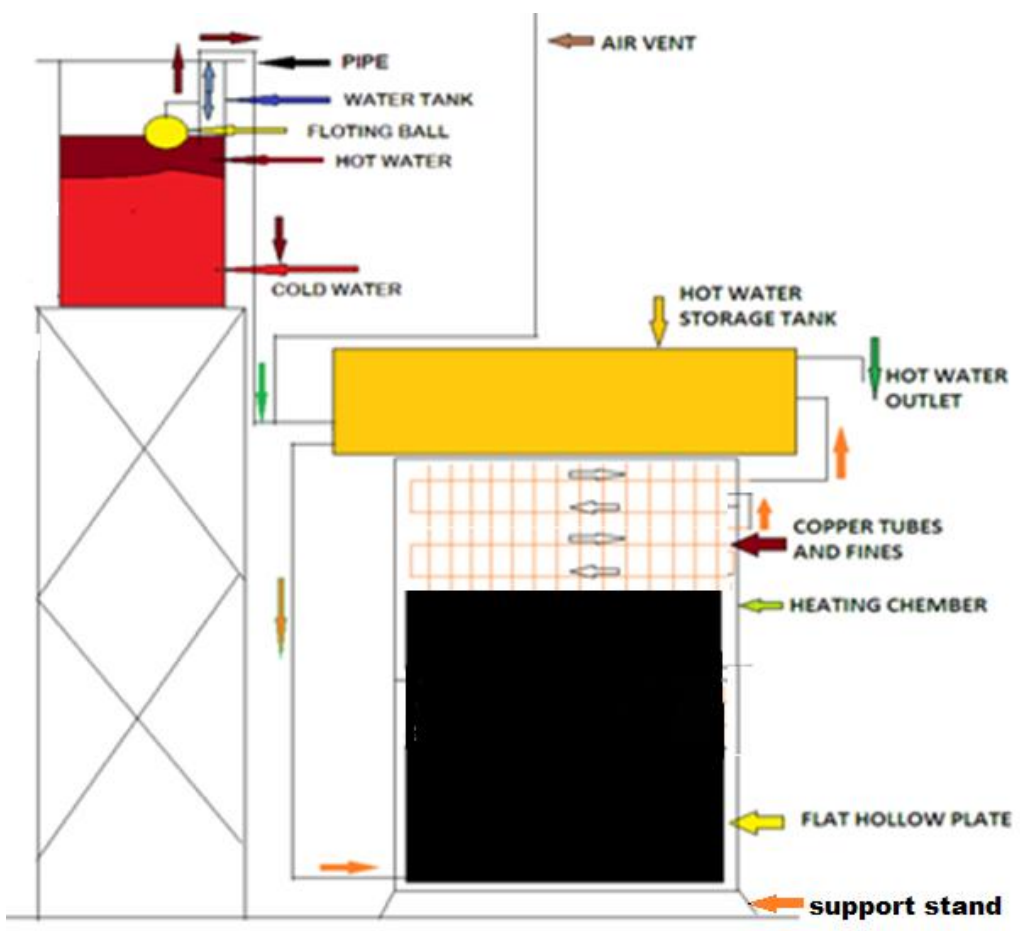

Fig.1 Schematic Diagram

For obtaining only the upper layer of hot water from the source tank there is a need of a special system. For this purpose we have constructed the extraction system which contains the floating ball and flexible pipe. By using the simple mechanism it affects greatly to the cost and efficiency of solar water heater. Ball floats on hot water and pipe is attached to it. Thus hot water from tank having temperature difference of $5-7^{\circ} \mathrm{C}$ as compared to the bottom layer of water in the source is obtained. The initial suction has to be performed and then the water flows due to the gravity. As the water level goes up and down the ball and pipe will also move accordingly due to the floating ball. This is the innovative part of this system because this concept is not used in any solar water heater and one of the reasons to reduce the cost of the present solar water heater. The hot water from the tank is provided in the Aluminum hollow plate having thickness 1 inch. The thickness of Aluminum foil is $2 \mathrm{~mm}$. This Plate is coated with black color so that it can absorb $98 \%$ solar energy incident on it. The length and breadth of the Aluminum plate is about $0.61 \times 0.91$ meter respectively in order to get more surface area and less water in it, so as to raise the temperature of the hot water extracted from the source tank with the help of the solar energy. The inlet is provided at the bottom of the plate and the outlet at the top to get hot water from the plate. This plate is placed inside the box having one side covered with toughened glass. Because of this glass the sun radiations are trapped inside the box and the solar water heater is able to provide the hot water even in cloudy and winter days. This plate works on the principle of more the surface area and lesser the quantity of water more will be the temperature of the water in less time. By the application of glass we are able to get hot water up to $78^{\circ} \mathrm{C}$. This water is then taken into copper pipe of $12.7 \mathrm{~mm}$ diameter. Here the superheating effect is given to the water which is taken from the Aluminum plate. 1.83 meter pipe is used for heating purpose.

Again the water is taken into another Aluminum flat plate having thickness $12.7 \mathrm{~mm}$ of same surface area. Here it gets again heated and again taken into next 1.83 meter copper pipe of $12.7 \mathrm{~mm}$ diameter. Again the water is collected into another Aluminum flat plate having thickness $12.7 \mathrm{~mm}$ of same surface area. Here it gets heated and again taken into next 1.83 meter copper pipe of $12.7 \mathrm{~mm}$ diameter. The hot water is taken to the thermal reservoir where it gets stored. The outlet of reservoir is given to the inlet of plate so that it can be a cyclic process. The outlet is also connected to the tap so that, if the consumer is willing to use the hot water in early morning also he can the hot water from the heater. When the consumer take the hot water from reservoir then the water in floating assembly will introduce in the reservoir so that the system should be full of water. In this way the Economical solar water heater works [Fig.1]. 


\section{Prototype of Economical solar water heater}

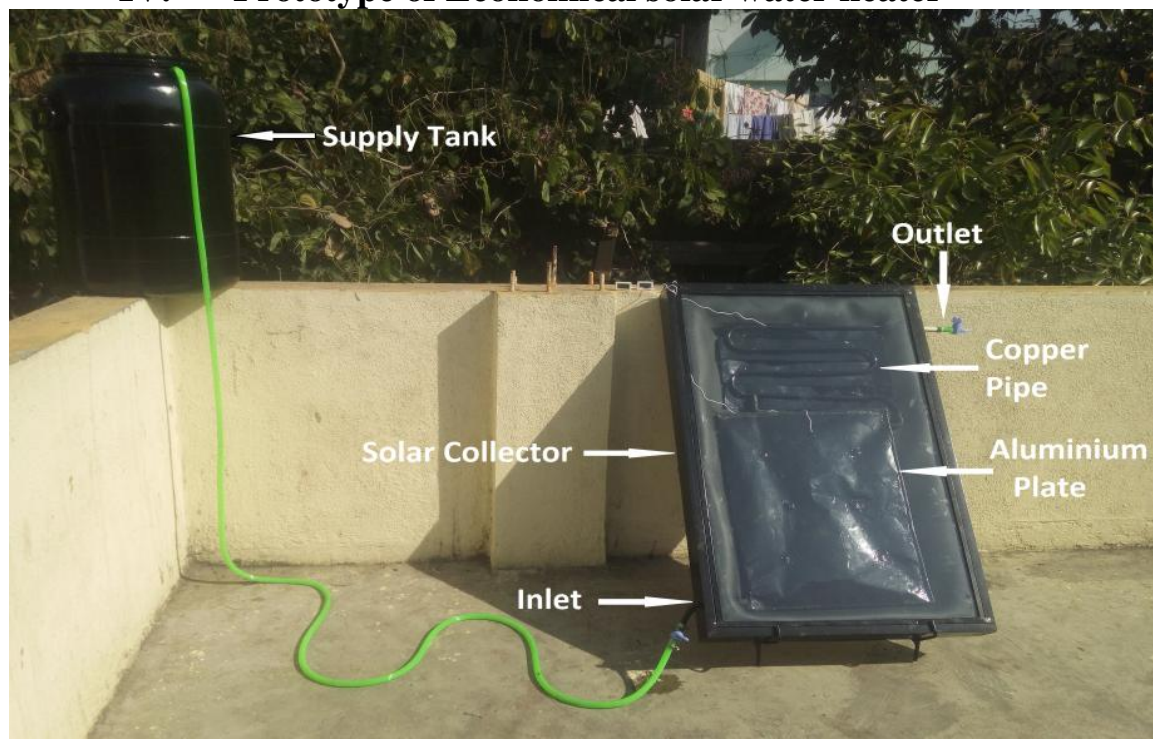

Fig. 2 Actual Prototype

Fig. 3 shows the graph of Output Temperature vs. Time of 3 Days. It is observed that peak water temperature for all the 3 days was same. Water heating takes place in 8 to 10 hours a day. i.e.(8AM To 5PM).

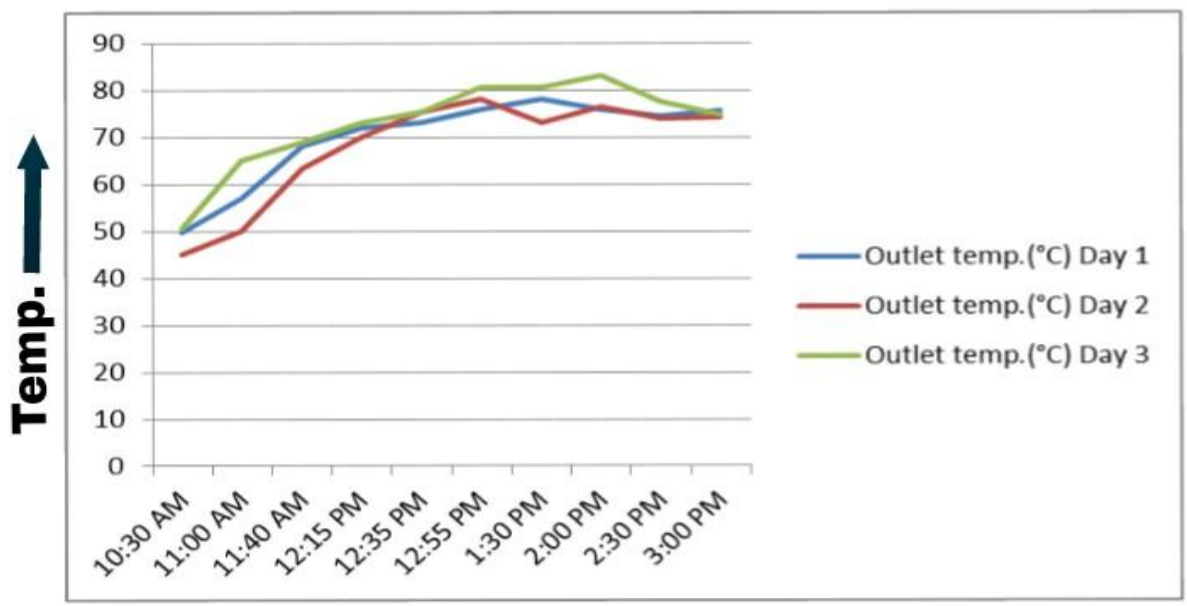

Time

\begin{tabular}{|c|c|c|c|c|c|c|}
\hline Time & $\begin{array}{c}\text { Ambient } \\
\text { Temp. }\end{array}$ & \multicolumn{2}{|c|}{ Supply tank $\left({ }^{\circ} \mathbf{C}\right)$} & $\begin{array}{c}\text { Aluminum } \\
\text { Plate Temp. }\end{array}$ & $\begin{array}{c}\text { Copper } \\
\text { Pipe } \\
\text { Temp. }\end{array}$ & $\begin{array}{c}\text { Outlet } \\
\text { Temp. }\end{array}$ \\
\hline & $\left({ }^{\circ} \mathbf{C}\right)$ & $\begin{array}{c}\text { Upper } \\
\text { Temp. }\end{array}$ & $\begin{array}{c}\text { Bottom } \\
\text { Temp. }\end{array}$ & $\left({ }^{\circ} \mathbf{C}\right)$ & $\left({ }^{\circ} \mathbf{C}\right)$ & $\left({ }^{\circ} \mathbf{C}\right)$ \\
\hline $10: 30 \mathrm{AM}$ & 24.8 & 23 & 21 & 49 & 80 & 49.8 \\
\hline $11: 00 \mathrm{AM}$ & 25.5 & 24 & 21.8 & 57.3 & 90 & 57 \\
\hline $11: 40 \mathrm{AM}$ & 26.3 & 25 & 22.2 & 72 & 98 & 68 \\
\hline $12: 15 \mathrm{PM}$ & 27 & 26.7 & 23 & 88 & 105 & 72 \\
\hline $12: 35 \mathrm{PM}$ & 28 & 26.7 & 23.4 & 75 & 104.5 & 73 \\
\hline $12: 55 \mathrm{PM}$ & 28 & 26.9 & 23.5 & 81 & 105.2 & 76 \\
\hline $1: 30 \mathrm{PM}$ & 28.5 & 27.5 & 23.8 & 84 & 106.6 & 78.2 \\
\hline $2: 00 \mathrm{PM}$ & 28.7 & 28 & 24.1 & 85 & 104.1 & 75.9 \\
\hline $2: 30 \mathrm{PM}$ & 28.5 & 29.5 & 25.3 & 83 & 102 & 74.6 \\
\hline $3: 00 \mathrm{PM}$ & 28.3 & 30.3 & 25.5 & 84 & 104.2 & 75.5 \\
\hline
\end{tabular}

Table 2. Observation Table 
Fig.3 Hourly records of outlet temperature

\begin{tabular}{|c|c|c|c|}
\hline Sr. No & Description of Item & Specification & Estimated Cost \\
\hline 1 & Floating Assembly & 0.30 Meter & $150 /-$ \\
\hline 2 & Aluminum Flat Plates & $\begin{array}{c}0.61 * 0.52 \text { Meter, } 2 \mathrm{~mm} \\
\text { thick }\end{array}$ & $500 /-$ \\
\hline 3 & Frame & Mild steel & $2100 /-$ \\
\hline 5 & Copper Pipes & 3 Meter,12.7 mm Dia & $1000 /-$ \\
\hline 6 & Thermal Reservoir & Capacity-100 liters & $6000 /-$ \\
\hline 8 & Supporting Stand & $8 * 5$ feet & $300 /-$ \\
\hline 9 & Insulation & Superlone & $3700 /-$ \\
\hline 10 & PVC Piping & 5 meter, 12.7 mm Dia & $\mathbf{1 1 , 1 2 0 / -}$ \\
\hline
\end{tabular}

Table 1. Project Costing

Table 2 shows the observations at various time intervals in a day. The Maximum temperature difference between inlet and outlet temperature is $50.7^{\circ} \mathrm{C}$. The temperature difference between upper and bottom layer water in supply tank is $4.8^{\circ} \mathrm{C}$.The maximum output temperature occurs between $12.30 \mathrm{PM}$ to $2 \mathrm{PM}$. These

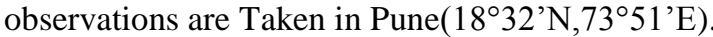

\section{Conclusion}

1. It is found that combine use of Copper and Aluminium reduces the cost of Economical Solar Water Heater.

2. The floating assembly gives 5 to $7^{\circ} \mathrm{C}$ initially heated water from the supply tank.

3. The aluminum flat plate gives maximum $65^{\circ} \mathrm{C}$ hot water to the inlet of copper pipes.

4. The maximum temperature of copper pipe is $107^{\circ} \mathrm{C}$.

5. The maximum outlet temperature is $78^{\circ} \mathrm{C}$.

6. By using proper insulating material efficiency of solar water heater is found to be increased.

\section{References}

[1]. A. Jamar, Z.A.A. Majid and W.H. Azmi, A review of water heating system for solar energy application, International Communications in heat \& mass transfer 76, 2016,178-187

[2]. Nosa Andrew Ogie, Ikponmosa Oghogho and Julius Jesumirewhe, Design and construction of Solar water heater based on the thermo syphon principle, Journal of Fundamentals of Renewable Energy and application, Vol.3, 2013, Article ID- 235592

[3]. Andrei Stefan JERCAN, The simplified calculus of flat plate solar collector, Annals of the University of Craiova, Electrical Engineering series, No.30, 2006.

[4]. Madhukeshawa N and E.S. Prakash, An investigation on the performance characteristics of solar flat plate collector with different selective surface coatings, International Journal of Energy \& Environment , 3(1),2012,99-108.

[5]. Fabio struckman, Analysis of Flat plate solar collector, Project report 2008 MVK160 Heat and mass transport, May 08 2008, Lund, Sweden.

[6]. Suhas P. Sukhatme and J K Nayak, Solar Energy (New Delhi, McGraw Hill Education (India) Private Limited, 2015) 